\title{
Clinical profile of recurrent community-acquired pneumonia in children
}

\author{
Francesca Patria ${ }^{1}$, Benedetta Longhi ${ }^{1}$, Claudia Tagliabue ${ }^{1}$, Rossana Tenconi ${ }^{1}$, Patrizia Ballista ${ }^{2}$, Giuseppe Ricciardi ${ }^{2}$, \\ Carlotta Galeone ${ }^{3}$, Nicola Principi ${ }^{1}$ and Susanna Esposito ${ }^{1 *}$
}

\begin{abstract}
Background: The aim of this case-control study was to analyse the clinical characteristics of children with recurrent community-acquired pneumonia (rCAP) affecting different lung areas (DLAs) and compare them with those of children who have never experienced CAP in order to contribute to identifying the best approach to such patients.

Methods: The study involved 146 children with $\geq 2$ episodes of radiographically confirmed CAP in DLA in a single year (or $\geq 3$ episodes in any time frame) with radiographic clearing of densities between occurrences, and 145 age- and gender-matched controls enrolled in Milan, Italy, between January 2009 and December 2012. The demographic and clinical characteristics of the cases and controls were compared, and a comparison was also made between the cases with rCAP (i.e. $\leq 3$ episodes) and those with highly recurrent CAP (hrCAP: i.e. $>3$ episodes).

Results: Gestational age at birth $(p=0.003)$, birth weight $(p=0.006)$, respiratory distress at birth $(p<0.001)$, and age when starting day care attendance $(p<0.001)$ were significantly different between the cases and controls, and recurrent infectious wheezing $(p<0.001)$, chronic rhinosinusitis with post-nasal drip $(p<0.001)$, recurrent upper respiratory tract infections $(p<0.001)$, atopy/allergy $(p<0.001)$ and asthma $(p<0.001)$ were significantly more frequent. Significant risk factors for hrCAP were gastroesophageal reflux disease (GERD; $p=0.04)$, a history of atopy and/or allergy $(p=0.005)$, and a diagnosis of asthma $(p=0.0001)$ or middle lobe syndrome $(p=0.001)$. Multivariate logistic regression analysis, adjusted for age and gender, showed that all of the risk factors other than GERD and wheezing were associated with hrCAP.

Conclusions: The diagnostic approach to children with rCAP in DLAs is relatively easy in the developed world, where the severe chronic underlying diseases favouring rCAP are usually identified early, and patients with chronic underlying disease are diagnosed before the occurrence of rCAP in DLAs. When rCAP in DLAs does occur, an evaluation of the patients' history and clinical findings make it possible to limit diagnostic investigations.
\end{abstract}

Keywords: Allergy, Asthma, Atopy, Children, Community-acquired pneumonia, Lower respiratory tract infection, Pneumonia, Recurrent pneumonia, Respiratory tract infection, Wheezing

\section{Background}

Recurrent community acquired pneumonia (rCAP) is not rare in children living in industrialised countries. The Isle of Wight birth cohort study of 1,336 children followed up for 10 years found a $7.4 \%$ prevalence of $\geq 2$ lower respiratory tract infections (LRTIs) including CAP [1]; a retrospective cohort study of German children aged 5-7 years found that $6.7-8.2 \%$ of the children had a positive history of CAP, $6.9-8.2 \%$ of whom had experienced rCAP [2]; and

\footnotetext{
* Correspondence: susanna.esposito@unimi.it

'Department of Pathophysiology and Transplantation, Pediatric Highly Intensive Care Unit, Università degli Studi di Milano, Fondazione IRCCS Ca' Granda Ospedale Maggiore Policlinico, Via Commenda 9, Milan 20122, Italy Full list of author information is available at the end of the article
}

data from Toronto's Hospital for Sick Children show that 238 of 2,900 children (8\%) admitted because of CAP met the criteria for rCAP [3].

Identifying the factors that can favour the development of a new CAP episode is critical for the implementation of appropriate preventive, diagnostic and therapeutic measures. However, although it is relatively easy to evaluate and treat cases occurring in the same lung region, it is more difficult in the case of rCAP developing in different lung areas (DLAs). Recurring lung densities in the same regions are almost invariably due to intra- or extraluminal bronchial obstruction, or structural abnormalities of the airways or lung parenchyma, and the recommended airway 
endoscopy and/or diagnostic imaging (sometimes in association with laboratory tests for tuberculosis and fungal diseases) is almost always sufficient to make a diagnosis [4]. On the contrary, rCAP affecting multiple lobes or different areas of the same lobe may be associated with a wide range of more or less severe clinical problems that could per se increase the risk of lung infection. As some of these can only be identified using specific laboratory and/or instrumental methods, diagnosing and treating patients with rCAP in DLAs can be particularly complicated and expensive, and is not always efficacious.

Various attempts have been made to define the most frequent causes of rCAP and establish the most rational diagnostic and therapeutic approach [5-9]. Unfortunately, the findings are frequently conflicting, and it is not possible to state whether the cause of rCAP in DLAs is necessarily a serious underlying diseases requiring immediate diagnosis.

The aim of this case-control study was to analyse the demographic and clinical characteristics as well as the predisposing factors of children with rCAP in DLAs and compare them with those of children who had never experienced CAP in order to contribute to identifying the best approach to such patients.

\section{Patients and methods \\ Patients}

We reviewed the medical records of all of the children aged $<14$ years who attended the Respiratory Disease Section of Pediatric Clinic 1, Department of Pathophysiology and Transplantation, University of Milan, Fondazione IRCCS Ca' Granda, Ospedale Maggiore Policlinico, Milan, Italy, between January 2009 and December 2012 because of rCAP. The patients were included in the analysis if they had experienced $\geq 2$ episodes of radiographically confirmed CAP in a single year (or $\geq 3$ episodes in any time frame) with radiographic clearing of densities between occurrences [10]. Only the children with rCAP in DLAs were enrolled, except for those with a diagnosis of cystic fibrosis identified in the first weeks of life who were excluded and followed up in accordance with specific diagnostic and therapeutic guidelines. The controls were age- and gendermatched children who had never experienced CAP, and for whom all of the data concerning their health problems since birth were available as they had been continuously followed at the same institution for the purpose of vaccinations and periodic evaluations of growth and psychological development.

The study was approved by the Ethics Committee of Fondazione IRCCS Ca' Granda. Ospedale Maggiore Policlinico, Milan, Italy, and written informed consent was obtained from the parents or legal guardian of all of the enrolled children.

\section{Methods}

A previously prepared electronic chart was used to record each enrolled child's age, gender, height, weight, gestational age, birth weight, respiratory complications at birth, duration of breast-feeding, the number of siblings, type of dwelling (i.e. urban or rural), household exposure to cigarette smoke, age when starting day care attendance, and the number and type of CAP episodes. We also recorded any underlying diseases possibly associated with CAP that had been diagnosed during hospitalisation or a visit to our outpatient clinic: i.e. oromotor incoordination and swallowing dysfunction predisposing to aspiration syndrome [11]; immune disorders, including atopy/allergy and primary and acquired immunodeficiency syndrome [12,13]; congenital heart defects [14]; lung and airway problems such as chronic rhinosinusitis with post-nasal drip [15], primary ciliary dyskinesia [16], recurrent wheezing $[17,18]$, bronchial asthma [13] or middle lobe syndrome [19]; gastroesophageal reflux disease (GERD) [20]; and overweight or obesity [21].

Aspiration syndrome was diagnosed clinically and confirmed by means of fluoroscopic feeding studies showing oropharyngeal incoordination. Immune function was determined by measuring serum immunoglobulin levels, IgG subclasses, $\mathrm{T}$ cell subpopulations, and complement assays. Atopy was diagnosed in the presence of total IgE levels of $\geq 2$ standard deviations (SDs) for age and/or allergen-specific IgE for common inhaled and food allergens. The diagnoses of allergy were based on clinical symptoms, skin tests and IgE determinations. Cardiac anomalies were confirmed by means of echocardiography. Chronic rhinosinusitis with post-nasal drip was clinically diagnosed in the presence of at least two of the following symptoms: a mucous or purulent nasal discharge for more than three months, nasal congestion, and posterior nasal drainage; in the case of doubt or the frequent recurrence of pulmonary infections, flexible optical fibre nasal endoscopy and/or paranasal sinus computed tomography were used to confirm the diagnosis and identify any mechanical obstructions of the upper airways. Nasal ciliary function was evaluated by measuring ciliary beat frequency in samples of ciliated epithelium from the inferior nasal turbinate; in patients with two pathological values, a further brushing was taken for ultrastructural analysis by means of electron microscopy. A diagnosis of suspected GERD was based on clinical history and the assessment of symptoms such as regurgitation, nausea, chest and/or abdominal pain, hoarseness and dysphagia; when the diagnosis was doubtful, or in the presence of refractory respiratory or gastrointestinal manifestations, the children underwent a 24-hour intraesophageal $\mathrm{pH}$ study. The percentage of body fat was calculated as the body mass index (BMI) SD in accordance with the World Health Organisation child growth 
standards. Recurrent wheezing in pre-school children was defined as at least three episodes of respiratory tract infections in a period of six months with parental reports of shortness of breath and physician-diagnosed dyspnea $[17,18]$. Bronchial asthma in school-age children was diagnosed in the presence of at least two episodes of wheezing, breathlessness, chest tightness, coughing, and pulmonary function test evidence of airflow limitation. Right middle lobe syndrome was defined as atelectasis persisting for more than 4-6 weeks or two or more episodes of consolidation of the right middle lobe.

\section{Statistical analysis}

The continuous variables are given as mean values \pm SD and were compared between groups using a twosided Student's $t$ test after checking that the data were normally distributed; and the categorical variables are given as numbers and percentages and were compared using contingency table analysis and the chi-squared or Fisher's test, as appropriate.

The odds ratios (ORs) of rCAP and corresponding 95\% confidence intervals (CIs) were computed using conditional logistic regression, stratified by gender and age.

In further analyses, comparisons were made between the children with rCAP (i.e. $\leq 3$ episodes) and those with hrCAP (i.e. $>3$ episodes). The hrCAP/rCAP ORs and CIs were computed using unconditional multiple logistic regression models, including terms for gender and age $(<7$ $v s \geq 7$ years old: i.e. median values).

All of the tests were two-sided and a p value of $<0.05$ was considered statistically significant. The data were analysed using SAS, version 9.1 (Cary, NC, USA).

\section{Results and discussion}

Table 1 shows the demographic characteristics of the 146 children with rCAP in DLAs and 145 controls enrolled in the study. The two groups were comparable in terms of gender and age distribution, the duration of breast-feeding, the type of dwelling, exposure to cigarette smoke and the number of siblings, but gestational age at birth $(p=0.003)$, birth weight $(\mathrm{p}=0.006)$, respiratory distress at birth $(\mathrm{p}<$ $0.001)$ and age when starting day care attendance $(\mathrm{p}=$ 0.001 ) were significantly different.

Table 2 shows the prevalence of possible predisposing factors in the two groups. Severe predisposing factors such as heart disease, oromotor incoordination and swallowing dysfunction, ciliary dyskinesia, and primary or acquired immunodeficiency were rare and never observed in the controls, but were diagnosed before rCAP in DLAs in the cases. Middle lobe syndrome was quite frequent among the cases but never reported among controls. GERD and obesity were relatively common in both groups, but some conditions involving the respiratory tract were more frequent in the children with rCAP.
Recurrent infectious wheezing was diagnosed in 113 cases $(77.4 \%)$ and in only 20 controls $(13.8 \%)(\mathrm{p}<0.001)$; chronic rhinosinusitis with post-nasal drip was diagnosed in respectively $105(71.9 \%)$ and six (4.1\%) ( $<<$ $0.001)$; recurrent upper respiratory tract infections in 99 $(67.8 \%)$ and $29(20.0 \%)(\mathrm{p}<0.001)$; atopy/allergy in 75 $(51.4 \%)$ and 17 (11.7\%; $\mathrm{p}<0.001)$; and asthma in 46 $(31.5 \%)$ and eight $(5.5 \%)(\mathrm{p}<0.001)$. The most important predisposing factors were rhinosinusitis, recurrent wheezing and asthma, which respectively increased the risk of rCAP by about 60, 32 and 10 times.

Table 3 compares the patients with $\operatorname{rCAP}$ ( $\leq 3$ episodes) and those with hrCAP ( $>3$ episodes), and shows that the significant risk factors for hrCAP were GERD $(p=0.04)$, a history of atopy and/or allergy $(p=0.005)$, a diagnosis of asthma $(\mathrm{p}=0.0001)$, and middle lobe syndrome $(p=0.001)$; the last three were confirmed in the multivariate logistic regression analysis adjusted for age and gender, which also indicated that wheezing was associated with hrCAP.

To the best of our knowledge, this is the first study carried out in an industrialised country evaluating the prevalence of factors that are thought to be associated with an increased risk of developing rCAP in DLAs in children with or without rCAP. As some of the factors associated with an increased risk of rCAP in DLAs are very common pediatric diseases, this approach should better define the real importance of each and simultaneously quantify the real weight of other potentially negative predisposing factors.

The study data suggest that children living in an industrialised country with a history of rCAP in DLAs can be divided into those suffering from a severe underlying disease that favours the development of CAP but also causes other significant signs and symptoms that frequently involve extra-respiratory sites, and those whose clinical history is no different from that of many children without rCAP. Some generally mild diseases were frequent in both groups, although slightly more among the cases; severe underlying diseases were fortunately very rare and had already been identified before they could cause rCAP. Heart disease, oromotor incoordination and swallowing dysfunction predisposing to aspiration syndrome, primary or acquired immunodeficiency syndrome, and primary ciliary dyskinesia were observed in very few cases, which indicates that the children had been adequately diagnosed and treated from their first months of life, thus significantly reducing the risk of multiple CAP episodes. The same can probably also be said of cystic fibrosis because neonatal screening in Milan allows the early identification of the vast majority of cases so that these patients were excluded. However, our findings are different from those of most other studies of the potential causes of $\operatorname{rCAP}[3,7,8]$. It has 
Table 1 Demographic characteristics of the study population

\begin{tabular}{|c|c|c|c|c|c|}
\hline & $\begin{array}{l}\text { Patients with rCAP } \\
\qquad(n=146)\end{array}$ & $\%$ & $\begin{array}{l}\text { Healthy controls } \\
\qquad(n=145)\end{array}$ & $\%$ & $\begin{array}{l}\text { Comparison between groups } \\
\qquad p^{*}\end{array}$ \\
\hline \multicolumn{6}{|l|}{ Gender } \\
\hline Female & 73 & 50.0 & 73 & 50.0 & \multirow[t]{2}{*}{0.95} \\
\hline Male & 73 & 50.0 & 72 & 50.0 & \\
\hline Age, mean $\pm S D$ (yrs) & $7.9 \pm 4.5$ & & $8.1 \pm 4.5$ & & 0.70 \\
\hline \multicolumn{6}{|c|}{ Gestational age (weeks) } \\
\hline$<32$ & 11 & 7.5 & 0 & 0 & \multirow{3}{*}{0.003} \\
\hline $32-36$ & 18 & 12.3 & 17 & 11.7 & \\
\hline$\geq 37$ & 117 & 80.2 & 128 & 88.3 & \\
\hline \multicolumn{6}{|l|}{ Birth weight (g) } \\
\hline$<750$ & 3 & 2.1 & 0 & 0 & \multirow{5}{*}{0.006} \\
\hline $750-1,000$ & 1 & 0.7 & 0 & 0 & \\
\hline $1,001-1,500$ & 7 & 4.8 & 0 & 0 & \\
\hline $1,501-2,500$ & 14 & 9.6 & 7 & 4.8 & \\
\hline$>2500$ & 121 & 82.8 & 138 & 95.2 & \\
\hline \multicolumn{6}{|c|}{ Respiratory distress at birth } \\
\hline Yes & 26 & 17.8 & 0 & 0 & \multirow[t]{2}{*}{$<0.001$} \\
\hline No & 120 & 82.2 & 145 & 100 & \\
\hline \multicolumn{6}{|c|}{ Breast-feeding $>3$ months } \\
\hline Yes & 83 & 58.4 & 85 & 58.6 & \multirow[t]{2}{*}{0.94} \\
\hline No & 59 & 41.6 & 60 & 41.4 & \\
\hline \multicolumn{6}{|l|}{ Type of dwelling } \\
\hline Urban & 127 & 87.0 & 124 & 85.5 & \multirow[t]{2}{*}{0.72} \\
\hline Rural & 19 & 13.0 & 21 & 14.5 & \\
\hline \multicolumn{6}{|c|}{ Exposure to cigarette smoke } \\
\hline Yes & 55 & 37.7 & 45 & 31.0 & \multirow[t]{2}{*}{0.23} \\
\hline No & 91 & 62.3 & 100 & 69.0 & \\
\hline \multicolumn{6}{|l|}{ Number of siblings } \\
\hline 0 & 48 & 32.9 & 45 & 31.0 & \multirow[t]{4}{*}{0.08} \\
\hline 1 & 66 & 45.2 & 74 & 51.0 & \\
\hline 2 & 26 & 17.8 & 26 & 17.9 & \\
\hline$\geq 3$ & 6 & 4.1 & 0 & 0 & \\
\hline \multicolumn{6}{|c|}{ Age starting day care attendance } \\
\hline$\leq 1$ year & 14 & 9.6 & 0 & 0 & \multirow[t]{5}{*}{$<0.001$} \\
\hline$>13-23$ months & 24 & 16.4 & 2 & 1.4 & \\
\hline 24-35 months & 33 & 22.6 & 40 & 27.6 & \\
\hline 36-47 months & 64 & 43.8 & 103 & 71.0 & \\
\hline$\geq 4$ years & 11 & 7.5 & 0 & 0 & \\
\hline
\end{tabular}

$r C A P$ : recurrent community-acquired pneumonia; $S D$ : standard deviation. *P values were calculated using Student's $t$ test, the chi-squared test or Fisher's test, as appropriate.

been reported that severe underlying diseases are not uncommon, may be unknown when a child with rCAP is examined for the first time and, consequently, may justify a more aggressive diagnostic approach in a large number of subjects. Owayed et al. examined the clinical records of 238 children with a history meeting the criteria for $\mathrm{rCAP}$, and found that $48 \%$ of them had aspiration syndrome, $10 \%$ immune disorders and 9\% congenital heart disease [3]. Adam found that about half of the children with rCAP that he studied had 
Table 2 Predisposing factors associated with CAP recurrences in children with rCAP and controls, and corresponding odds ratios (ORs) with $95 \%$ confidence intervals $(95 \% \mathrm{CI})$

\begin{tabular}{ccccc}
\hline $\begin{array}{c}\text { Patients with } \\
\text { rCAP }\end{array}$ & $\begin{array}{l}\text { Healthy } \\
\text { controls }\end{array}$ & $\begin{array}{c}\text { Comparison between } \\
\text { groups }\end{array}$ & OR $(95 \%$ Cl) \\
\hline$(n=146)$ & $\%$ & $(n=145)$ & $\%$ & $p^{\circ 0}$
\end{tabular}

\section{Predisposing factor}

Heart disease

$\begin{array}{cccccc}\text { Yes } & 3 & 2.1 & 0 & 0 & 0.25 \\ \text { No } & 143 & 97.9 & 145 & 100.0 & \end{array}$

Oro-motor incoordination/swal-lowing dysfunction

$\begin{array}{lccccc}\text { Yes } & 4 & 2.7 & 0 & 0 & 0.12 \\ \text { No } & 142 & 97.3 & 145 & 100.0 & \\ \text { Primary ciliary dyskinesia } & & & & & 1.00 \\ \text { Yes } & 1 & 0.7 & 0 & 0 & 100.0\end{array}$

Primary or acquired immunodeficiency

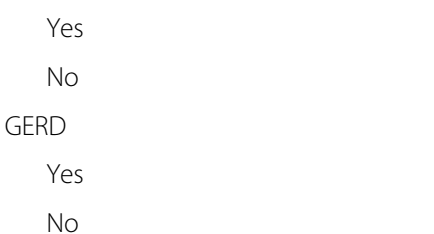

$\begin{array}{cccc}2 & 1.4 & 0 & 0 \\ 144 & 98.6 & 145 & 100.0 \\ 31 & 21.2 & 20 & 13.8 \\ 115 & 78.8 & 125 & 86.2\end{array}$

Overweight/obesity

$$
\begin{aligned}
& \text { BMI SD }<1 \\
& \text { BMI SD } \geq 1
\end{aligned}
$$

$\begin{array}{llll}112 & 76.7 & 119 & 82.1 \\ 34 & 23.3 & 26 & 17.9 \\ 113 & 77.4 & 20 & 13.8 \\ 33 & 22.6 & 125 & 86.2\end{array}$

0

Wheezing

Yes

Chronic rhinosinusitis with post-nasal drip

Yes

Middle lobe syndrome
Yes
No

$\begin{array}{ccccc}105 & 71.9 & 6 & 4.1 & <0.001 \\ 41 & 28.1 & 139 & 95.9 & \\ 44 & 30.1 & 0 & 0 & \\ 102 & 69.9 & 145 & 100.0 & <0.001\end{array}$

\begin{tabular}{|c|c|c|c|c|c|c|}
\hline Yes & 99 & 67.8 & 29 & 20.0 & $<0.001$ & $6.75(3.68-12.37)$ \\
\hline No & 47 & 32.2 & 116 & 80.0 & & $1^{\S \S}$ \\
\hline \multicolumn{7}{|c|}{ Atopy/allergy } \\
\hline Yes & 75 & 51.4 & 17 & 11.7 & $<0.001$ & $7.44(3.71-14.93)$ \\
\hline No & 71 & 48.6 & 128 & 88.3 & & $1^{\S \S}$ \\
\hline \multicolumn{7}{|l|}{ Asthma } \\
\hline Yes & 46 & 31.5 & 8 & 5.5 & $<0.001$ & $10.50(3.77-29.28)$ \\
\hline No & 100 & 68.5 & 137 & 94.5 & & $1^{\S \S}$ \\
\hline
\end{tabular}

Recurrent upper respiratory tract infections

Cl: confidence interval; BMI SD: body mass index standard deviation; GERD: gastroesophageal reflux diseae; OR: odds ratio. ${ }^{\circ} \mathrm{Chi}$-squared or Fisher's test, as appropriate; $r$ CAP: recurrent community-acquired pneumonia. ${ }^{\S} \mathrm{ORs}$ from conditional logistic regression model, stratified by gender and age. ${ }^{\S \S}$ reference category. 
Table 3 Comparison of predisposing factors between children with rCAP $(\leq 3)$ and those with hrCAP (>3 CAP)

\begin{tabular}{|c|c|c|c|c|c|c|}
\hline \multirow[t]{2}{*}{ Predisposing factor } & \multirow{2}{*}{$\begin{array}{c}\leq 3 \text { CAP } \\
\text { Total }(n=71)\end{array}$} & \multicolumn{3}{|c|}{$>3$ CAP } & \multirow{2}{*}{$\begin{array}{c}\text { Comparison between groups } \\
p^{\circ}\end{array}$} & \multirow[t]{2}{*}{ OR $(95 \% \mathrm{Cl})^{5}$} \\
\hline & & $\%$ & Total $(n=75)$ & $\%$ & & \\
\hline \multicolumn{7}{|l|}{ GERD } \\
\hline Yes & 10 & 14.1 & 21 & 28.0 & 0.04 & $2.34(0.07-5.69)$ \\
\hline No & 61 & 85.9 & 54 & 72.0 & & $1^{\S \S}$ \\
\hline \multicolumn{7}{|l|}{ Overweight/obesity } \\
\hline BMI SD $<1$ & 58 & 81.7 & 54 & 72.0 & 0.53 & $1^{\S \S}$ \\
\hline BMI SD $\geq 1$ & 13 & 18.3 & 21 & 28.0 & & $2.18(0.53-8.91)$ \\
\hline \multicolumn{7}{|l|}{ Wheezing } \\
\hline Yes & 51 & 71.8 & 62 & 82.7 & 0.056 & $2.43(1.02-5.79)$ \\
\hline No & 20 & 28.2 & 13 & 17.3 & & $1^{\S \S}$ \\
\hline \multicolumn{7}{|c|}{ Chronic rhinosinusitis with post nasal drip } \\
\hline Yes & 46 & 64.8 & 59 & 78.7 & 0.06 & $1.97(0.91-4.27)$ \\
\hline No & 25 & 35.2 & 16 & 21.3 & & $1^{\S \S}$ \\
\hline \multicolumn{7}{|l|}{ Middle lobe syndrome } \\
\hline Yes & 12 & 16.9 & 32 & 42.7 & & $3.02(1.36-6.71)$ \\
\hline No & 59 & 83.1 & 43 & 57.3 & $<0.001$ & $1^{\S \S}$ \\
\hline \multicolumn{7}{|c|}{ Recurrent upper respiratory tract infections } \\
\hline Yes & 47 & 66.2 & 52 & 69.3 & 0.69 & $1.33(0.64-2.80)$ \\
\hline No & 24 & 33.8 & 23 & 30.7 & & $1^{\S \S}$ \\
\hline \multicolumn{7}{|l|}{ Atopy/allergy } \\
\hline Yes & 28 & 39.4 & 47 & 62.7 & 0.005 & $2.20(1.10-4.42)$ \\
\hline No & 43 & 60.6 & 28 & 37.3 & & $1^{\S \S}$ \\
\hline \multicolumn{7}{|l|}{ Asthma } \\
\hline Yes & 11 & 15.5 & 35 & 46.7 & $<0.001$ & $3.46(1.48-8.08)$ \\
\hline No & 60 & 84.5 & 40 & 53.3 & & $1^{\S \S}$ \\
\hline
\end{tabular}

Cl: confidence interval; $B M I S D$ : body mass index standard deviation; GERD: gastroesophageal reflux disease; OR: odds ratio; ${ }^{\circ}$ Chi-squared test; ${ }^{5}$ estimates from multiple logistic regression models, including terms for gender and age ( $<7 \mathrm{vs} \geq 7$ years old, median values); ${ }^{5 \S}$ reference category.

immunodeficiency or immotile cilia syndrome [22]. Another retrospective study investigating the cause of rCAP in 70 Indian children found that the most frequent illness was recurrent aspiration, followed by immunodeficiency [7], and a more recent Spanish study found that congenital cardiac defects and aspiration syndrome were the most represented illnesses [8]. However, most of these studies were carried out some years ago and some were conducted in the developing world, where there is still a lack of basic services, high morbidity and mortality rates, and where the identification of severe underlying diseases leading to rCAP is regularly delayed.

Unlike severe diseases, mild to moderate respiratory infections were significantly more frequent in our children with rCAP, which seemed to be significantly associated with wheezing, chronic rhinosinusitis with postnasal drip, atopy/allergy and asthma. Recurrent respiratory tract infections are common in otherwise healthy children during the first years of life [23] because of the relative immaturity of the immune system, and they can lead to more severe disease in atopic and allergic children, and those with wheezing or asthma [23-25]. Most of our patients with rCAP in DLAs were simultaneously affected by all of these conditions, which suggests that the concurrence of several factors simply increased the clinical evidence of a natural phenomenon but had no particular clinical implication. Consequently, such children only need to undergo the preventive and therapeutic measures usually prescribed for recurrent respiratory infections and wheezing.

Although chronic rhinosinusitis with post-nasal drip is a common childhood disease [26,27], it is not usual to examine the upper airways and seek a purulent discharge inside the nasal cavities in children with a history of rCAP. However, on the basis of our results, it is important to start thinking in terms of nose-lung interactions as in the case of the relationship between allergic rhinitis and asthma [28]. The relevance of asthma as a possible cause of rCAP has been reported by a number of authors, and seems to be strictly related to the quality of asthma control $[17,28,29]$. The lung function of children whose asthma is 
well controlled by inhaled corticosteroids is normal, and they experience very few (if any) lower respiratory tract infections. Consequently, they do not need a particularly aggressive diagnostic approach and should simply be prescribed adequate asthma prophylactic therapy. A limitation of our study is represented by the absence of etiologic data on CAP episodes reported in the study population. It is possible that a proportion of children presenting with CAP have had a viral rather than bacterial cause of rCAP. Viral infections have been frequently associated with atopy, asthma and allergy [30,31] and these viral infections could explain our findings. However, also CAP due to atypical as typical bacteria can be associated with asthma $[18,32,33]$.

In the case of right middle lobe syndrome associated with hrCAP, our data support the prompt use of physiotherapy with a positive pressure mask in order to aid regional lung clearance and avoid CAP recurrences [34]. Some authors have found a relationship between right middle lobe syndrome and asthma $[34,35]$ but the small number of patients in our series prevents us from confirming or refuting this finding.

We did not find that GERD increased the risk of rCAP, although it may be associated with more frequent recurrences. This is not in line with the findings of some uncontrolled studies $[3,7,9]$ but as GERD is a common disease, it is possible that the observed relationship was only casual. In any case, GERD can be easily diagnosed on the basis of gastrointestinal complaints and treated without any further laboratory or radiological investigations.

Our findings indicate that prematurity, a low birth weight and respiratory distress at birth are independent factors associated with rCAP. The widely reported importance of chronic respiratory morbidity in prematurely born infants is due to their smaller and hyper-responsive airways [36-38], and there is also evidence that they may also have a genetic predisposition to viral infections [39], a combination that can facilitate catarrhal obstruction of the airways and lung inflammation. Up to $73 \%$ of pre-term infants with pulmonary bronchodysplasia require readmission to hospital because of lower respiratory tract diseases in the first years of life, and chronic respiratory morbidity requiring the use of healthcare facilities remains even at school age [40]. It should be investigated whether, in addition to adequate vaccinations, all pre-term babies and those with respiratory distress at birth would benefit from regular chest physiotherapy during respiratory illnesses in order to enhance secretion mobilisation and prevent recurrent infections. Moreover, as most of our children with rCAP were allergic and asthmatic, our finding that early day care attendance seemed to protect against rCAP supports the idea that the so-called "hygiene hypothesis" (i.e. exposure to a wide variety of pathogens protects against atopy and asthma) might also apply to rCAP [41].

\section{Conclusions}

In brief, our findings show that the diagnostic approach to children with rCAP in DLAs used in the developed world is relatively easy in most cases, and the severe underlying diseases favouring rCAP are usually identified early. Furthermore, when episodes of rCAP in DLAs do occur, an adequate evaluation of the patient's history and clinical findings is usually sufficient. Except for prematurity, the factors predisposing children to develop rCAP in DLAs are of limited clinical importance and do not need any particular diagnostic measures. Wheezing, chronic rhinosinusitis with postnasal drip, atopy/allergy and asthma seem to be the main factors associated with CAP recurrences and, in their presence, children with rCAP can be followed up by means of the same procedures as those usually used in the case of children without rCAP. Our findings have relevance in terms of informing future research on potential risk factors for recurrent CAP, although a more complicated approach is needed in the third world, where the early identification of the severe underlying diseases favouring rCAP is significantly more difficult or even impossible.

\section{Abbreviations \\ BMI: Body mass index; DLA: Different lung areas; GERD: Gastroesophageal reflux disease; OR: Odds ratio; rCAP: recurrent community-acquired pneumonia; SD: Standard deviation.}

\section{Competing interests}

The authors declare that they have no competing interests.

\section{Authors' contributions}

MFP drafted the manuscript, and was head of the outpatient clinic at which the patients with rCAP were enrolled; $B L, C T, R T, P B$ and $G R$ participated in the enrolment of the rCAP patients and otherwise healthy subjects; CG made the statistical analysis; NP revised the draft of the manuscript and made a substantial scientific contribution; SE coordinated and supervised the enrolment of the rCAP patients and otherwise healthy subjects, and cowrote the draft manuscript. All of the authors read and approved the final version of the manuscript.

\section{Acknowledgements}

This study was supported by grants from the Italian Ministry of Health (Bando Giovani Ricercatori 2007).

\section{Author details}

${ }^{1}$ Department of Pathophysiology and Transplantation, Pediatric Highly Intensive Care Unit, Università degli Studi di Milano, Fondazione IRCCS Ca' Granda Ospedale Maggiore Policlinico, Via Commenda 9, Milan 20122, Italy. ${ }^{2}$ Pediatric Unit Ospedale Bassini Istituti Clinici di Perfezionamento, Cinisello Balsamo (Milan), Italy. ${ }^{3}$ Department of Clinical Sciences and Community Health, University of Milan, Milan, Italy.

Received: 11 August 2013 Accepted: 18 September 2013

Published: 10 October 2013

\section{References}

1. Karmaus W, Dobai AL, Ogbuanu I, Arshard SH, Matthews S, Ewart S: Longterm effects of breastfeeding, maternal smoking during pregnancy, and recurrent lower respiratory tract infections on asthma in children. J Asthma 2008, 45:688-695.

2. Weigl JAI, Bader HM, Everding A, Schmitt HJ: Population-based burden of pneumonia before school entry in Schleswig-Holstein, Germany. Eur J Pediatr 2003, 162:309-316. 
3. Owayed AF, Campbell DM, Weng EE: Underlying causes of recurrent pneumonia in children. Arch Pediatr Adolesc Med 2000, 154:190-194.

4. Panitch HB: Evaluation of recurrent pneumonia. Pediatr Infect Dis J 2005, 24:265-266.

5. Bush A: Recurrent respiratory infections. Pediatr Clin N Am 2009, 56:67-100.

6. Wald ER: Recurrent and non-resolving pneumonia in children. Semin Resp Infect 1993, 8:46-58.

7. Lodha R, Puranik M, Natchu UCM, Kabra SK: Recurrent pneumonia in children: clinical profile and underlying causes. Acta Paediatr 2002, 91:1170-1173.

8. Cabezuelo Huerta G, Vidal Micó S, Abeledo Gómez A, Frontera Izquierdo P: Underlying causes of recurrent pneumonia. An Pediatr (Barc) 2005, 63:409-412.

9. Ciftçi $E$, Günes M, Köksal $Y$, Ince E, Dogru U: Underlying causes of recurrent pneumonia in Turkish children in a university hospital. $J$ Trop Pediatr 2003, 49:212-215.

10. Wald ER: Recurrent and nonresolving pneumonia in children. Semin Respir Infect 1993, 8:46-58.

11. De Benedictis FM, Carnielli VP, De Benedictis D: Aspiration lung disease. Pediatr Clin North Am 2009, 56:173-190.

12. Sato $\mathrm{S}$, Kiyono $\mathrm{H}$ : The mucosal immune system of the respiratory tract Curr Opin Virol 2012, 2:225-232.

13. Holtzman MJ: Asthma as a chronic disease of the innate and adaptive immune systems responding to viruses and allergens. J Clin Invest 2012, 122:2741-2748.

14. Delacourt C, Hadchouel A, Toelen J, Rayyan M, De Blic J, Deprest J: Long term respiratory outcomes of congenital diaphragmatic hernia, esophageal atresia, and cardiovascular anomalies. Semin Fetal Neonatal Med 2012, 17:105-111.

15. Guilemany JM, Alobid I, Mullol J: Controversies in the treatment of chronic rhinosinusitis. Expert Rev Respir Med 2010, 4:463-477.

16. Ferkol TW, Leigh MW: Ciliopathies: the central role of cilia in a spectrum of pediatric disorders. J Pediatr 2012, 160:366-371.

17. Patria MF, Esposito S: Recurrent lower respiratory tract infections in children: a practical approach to diagnosis. Pediatr Respir Rev 2013, 14:53-60.

18. Esposito S, Blasi F, Arosio C, Fioravanti L, Fagetti L, Droghetti R, Tarsia P, Allegra L, Principi N: Importance of acute Mycoplasma pneumoniae and Chlamydia pneumoniae infections in children with wheezing. Eur Respir J 2000, 16:1142-1146

19. Gudbjartsson T, Gudmundsson G: Middle lobe syndrome: a review of clinicopathological features, diagnosis and treatment. Respiration 2012, 84:80-86.

20. Berquist WE, Rachelefsky GS, Kadden M, Siegel SC, Katz RM, Fonkalsrud EW, Ament ME: Gastroesophageal reflux-associated recurrent pneumonia and chronic asthma in children. Pediatrics 1981, 68:29-35.

21. Tracey W, De NC, Harper JR: Obesity and respiratory infection in infants and young children. Br Med J 1971, 1(5739):16-18.

22. Acam KAR: Persistent or recurrent pneumonia in Saudi children seen at King Khalid University Hospital, Riyadh: clinical profile and some predisposing factors. Ann Trop Paediatr 1991, 11:129-135.

23. Everard ML: 'Recurrent lower respiratory tract infections' - going around in circles, respiratory medicine style. Paediatr Respir Rev 2012, 13:139-143.

24. James KM, Peebles RS Jr, Hartert TV: Response to infections in patients with asthma and atopic disease: an epiphenomenon or reflection of host susceptibility? J Allergy Clin Immunol 2012, 130:343-351.

25. Duse M, Leonardi L, Zicari AM, De Castro G, Indinnimeo L: Risk factors for upper airway diseases. Int J Immunopathol Pharmacol 2010, 23(1 Suppl):13-15

26. Esposito S, Bosis S, Bellasio M, Principi N: From clinical practice to guidelines: how to recognize rhinosinusitis in children. Pediatr Allergy Immunol 2007, 18(Suppl):48-50.

27. Revai K, Dobbs LA, Nair S, Patel J, Grady JJ, Chonmaitree T: Incidence of acute otitis media and sinusitis complicating upper respiratory tract infection: the effect of age. Pediatrics 2007, 119:e1408-e1512.

28. Passalacqua G, Ciprandi G, Canonica GW: The nose-lung interaction in allergic rhinitis and asthma: united airways disease. Curr Opin Allergy Clin Immunol 2001, 1:7-13.

29. Bisgaard H, Szefler S: Prevalence of asthma-like symptoms in young children. Pediatr Pulmonol 2007, 42:723-728.

30. De Boek K, Willems T, Van Gysel D, Corbeel L, Eeckels R: Outcome after right middle lobe syndrome. Chest 1995, 108:150-152.
31. Busse WW, Lemanske RF Jr, Gern JE: Role of viral respiratory infections in asthma and asthma exacerbations. Lancet 2010, 376:826-834.

32. Jackson DJ, Johnston SL: The role of viruses in acute exacerbations of asthma. J Allergy Clin Immunol 2010, 125:1178-1187.

33. Papadopoulos NG, Christodoulou I, Rohde G, Agache I, Almqvist C, Bruno A, Bonini S, Bont L, Bossios A, Bousquet J, Braido F, Brusselle G, Canonica GW Carlsen KH, Chanez P, Fokkens WJ, Garcia-Garcia M, Gjomarkaj M, Haahtela T, Holgate ST, Johnston SL, Konstantinou G, Kowalski M, Lewandowska-Polak A, Lødrup-Carlsen K, Mäkelä M, Malkusova I, Mullol J, Nieto A, Eller E, et al: Viruses and bacteria in acute asthma exacerbations -A GA ${ }^{2}$ LEN.DARE* systematic review. Allergy 2011, 66:458-468.

34. Talbot TR, Hartert TV, Mitchel E, Halasa NB, Arbogast PG, Poehling KA, Schaffner W, Craig AS, Griffin MR: Asthma as a risk factor for invasive pneumococcal disease. N Engl J Med 2005, 352:2082-2090.

35. Priftis KN, Anthracopoulos MB, Mermiri D, Papadopoulou A, Xepapadaki P, Tsakanika C, Nicolaidou P: Bronchial hyperresponsiveness, atopy, and bronchoalveolar lavage eosinophils in persistent middle lobe syndrome. Pediatr Pulmonol 2006, 41:805-811.

36. Greenough A: Long term respiratory outcomes of very premature birth (<32 weeks). Semin Fetal Neonatal Med 2012, 17:73-76.

37. Greenough A: Long-term pulmonary outcome in the preterm infant. Neonatology 2008, 93:324-327.

38. Greenough A, Limb E, Marstin L, Marlow N, Calvert S, Peacock J: Risk factors for respiratory morbidity in infancy following very premature birth. Arch Dis Child 2005, 90:F320-F323.

39. Siezen $\mathrm{CL}$, Bont $\mathrm{L}$, Hodemaekers HM, Ermers MJ, Doornbos G, Van't Slot $\mathrm{R}$, Wijmenga C, Houwelingen HC, Kimpen JL, Kimman TG, Hoebee B, Janssen R: Genetic susceptibility to respiratory syncytial virus bronchiolitis in preterm children is associated with airway remodeling genes and innate immune genes. Pediatr Infect Dis J 2009, 28:333-335.

40. Fawke J, Lum S, Kirkby J, Hennessy E, Marlow N, Rowell V, Thomas S, Stocks $\mathrm{J}$ : Lung function and respiratory symptoms at 11 years in children born extremely preterm: the EPICure study. Am J Respir Crit Care Med 2010, 182:237-245.

41. Fishbein $A B$, Fuleihan RL: The hygiene hypothesis revisited: does exposure to infectious agents protect us from allergy? Curr Opin Pediatr 2012, 24:98-102

doi:10.1186/1471-2466-13-60

Cite this article as: Patria et al:: Clinical profile of recurrent communityacquired pneumonia in children. BMC Pulmonary Medicine 2013 13:60.

\section{Submit your next manuscript to BioMed Central and take full advantage of:}

- Convenient online submission

- Thorough peer review

- No space constraints or color figure charges

- Immediate publication on acceptance

- Inclusion in PubMed, CAS, Scopus and Google Scholar

- Research which is freely available for redistribution 